\title{
Induction of Labor with PGE2 after One Previous Cesarean Section: 18 Years Experience in a University Hospital
}

\author{
Nourah Al Qahtani, Sameera Al Borshaid, Hissa Al Enezi \\ King Fahad University Hospital, University of Dammam, Dammam, Saudi Arabia. \\ Email: dr.nourah@gmail.com
}

Received July 23 $3^{\text {rd }}$, 2010; revised October $19^{\text {th }}$, 2010; accepted November $11^{\text {th }}, 2010$.

\begin{abstract}
Objective: To review the outcome of prostaglandin induction of labor in term pregnant women with previous one cesarean section compared to those without previous Cesarean section. Design: 18 years retrospective review of hospital records and case note review of index cases. Setting: University hospital. Population: Three hundred and twenty two women who had their labor induced with prostaglandin E2. One hundred and sixty one women had one previous Cesarean section. Methods: This study was conducted at King Fahad University Hospital, University of Dammam. It is a tertiary referral center with approximately 2300 births per year. We searched the hospital's records of deliveries from January 1992 to December 2009 and reviewed all indications and outcomes of prostaglandin induction of labor in women with one previous Cesarean section. The control group was composed of women who had their labor induced with prostaglandin but without previous Cesarean section. Main outcome measures: Labor outcome and uterine rupture Results: Three hundred and twenty two women were included. All received prostaglandin E2 for induction of labor. One hundred and sixty one women had one previous Cesarean section (study group) and the rest had no previous Cesarean section (control group). There was no difference in the rate of vaginal delivery between study and control group, $68.3 \%$ and $79.5 \%$ ( $p$ value 0.3 ), respectively. The rate of uterine rupture was 30 times higher in study group (2.5\% Vs $0.033 \%)$. Conclusion: In women with one previous Cesarean section, induction of labor with prostaglandin leads to comparable rate of vaginal delivery similar to those without prior Cesarean section but with relatively high risk of uterine rupture.
\end{abstract}

Keywords: Prostaglandin, Induction of Labor, Previous Cesarean Section, Retrospective

\section{Introduction}

Before the 1970s, deliveries by Cesarean section were considered as an indication for cesarean section in subsequent deliveries. In the 1980 s the dictum "once a Cesarean, always a Cesarean” was revised and attempt of vaginal delivery after Cesarean section (VBAC) was proposed to reduce the Cesarean section rate. The VBAC rate increased from $3 \%$ in 1980 to $28.3 \%$ in 1996, but unfortunately this was not associated with decrease in Cesarean section rate [1].

There has been a dramatic rise in Cesarean section rate over the last decades. The Cesarean section rate increased from $5.5 \%$ in 1970 to $31.8 \%$ in 2007, about one mother in three now gives birth by cesarean section, a record level for the United States [2]. The overall
Caesarean delivery rate in England for 2006-2007 was $24.3 \%$; the majority was emergency (14.7\%) rather than elective (9.5\%) Caesarean births. Hence, around $10 \%$ of the obstetric population has experienced prior Caesarean delivery [3]. This trend is also occurring in almost all developed and many developing countries.

Recent studies reaffirm earlier World Health Organization recommendations about optimal cesarean section rates. The best outcomes for mothers and babies appear to occur with cesarean section rates of $5 \%$ to $10 \%$. Rates above $15 \%$ seem to do more harm than good [4].

A national audit, conducted in England and Wales in 2000-2001, reported that the primary Caesarean section rate (rate for women who have not had a previous 
Caesarean section, regardless of parity) was $16.7 \%$, whereas, the repeat Caesarean section rate (rate for women who have had at least one previous Caesarean delivery) was $67.2 \%$.

Therefore, to reduce the overall Caesarean delivery rate, strategies are required that prevent the primary Caesarean delivery, improve uptake of VBAC and improve planned VBAC success. It has been estimated that increased uptake of planned VBAC could decrease the overall Caesarean delivery rate by around $5 \%$. Recent data suggest that VBAC may not be as safe as originally thought. This coupled with the safety of elective repeat Cesarean section (ERCS) at 39 weeks gestation, reduced hospital recovery time of ERCS (one-quarter spent 4 days or more recovering in hospital in 2006-2007, compared with just under one-third in 2005-2006) and current preference for lower parity, may encourage women with previous Caesarean birth to opt for ERCS rather than VBAC [3].

In Saudi Arabia, the current preference is for higher parity.The mean family size of household respondents from Saudi Arabia was 6.53 members [5]. So, emphasis is highly put on avoiding repeated Cesarean deliveries. Multiple Cesarean sections has been shown to be associated with higher maternal morbidity and mortality. The overall morbidity rises continually with each successive Cesarean section specifically for major morbidity from the triad of placenta previa, placenta accreta and hysterectomy [6]. Decreasing the primary Cesarean section is important as well as increasing the uptake of VBAC. The problem arises when the pregnant women with prior Cesarean section do not go into spontaneous labor and the need for induction arises. It has been shown that augmentation of labor in women with previous Cesarean section is safe when oxytocin is used judiciously [7]. There is less convincing evidence for the use of prostaglandin for induction of labor (IOL) in these women.

In this study, induction of labor using prostaglandin E2 in patients with previous Cesarean section was reviewed and compared to IOL in women with unscarred uterus.

\section{Materials and Methods}

All women with one previous lower segment Cesarean section who had labor induced with prostaglandin during 1992 and 2009 were studied. Information was obtained from obstetric ward data at King Fahad University Hospital, University of Dammam, Saudi Arabia. We did not include patients prior to 1992 as there was difficulty in getting files older than 1992. All the files for these patients were retrieved and data were collected.

In the period between 1992 and 2009, there were
42,485 deliveries. There were 161 patients with previous lower segment Cesarean section who were induced with prostaglandin, study group. The control group was made up of 161 matched pregnant women who have unscarred uterus and had labor induced with prostaglandin. The following variables were recorded for both groups: maternal age, gravidity, parity, gestational age, reason for induction of labour, mode of delivery, neonatal outcome and maternal and neonatal complications. The dose and frequency of prostaglandin administration was also recorded. The primary outcome measure was the incidence of repeat Cesarean section. The incidence of uterine scar rupture was recorded. Statistical analysis was performed using GraphPad software. Student $t$ test, chi squared and Fisher's exact test were used as appropriate.

\section{Results}

During the 18 years reviewed, the total number of babies delivered in the hospital weighing $500 \mathrm{~g}$ or more was 42,485. The overall Cesarean section rate was $13.2 \%$ and the induction rate was $11 \%$. The rate of Cesarean section increased from $7.2 \%$ in 1992 to $23.4 \%$ in 2009. Of the total number of women admitted to labor room, 161 had previous one Cesarean section and labor was induced with prostaglandin. These patients (study group) were matched with a group who received prostaglandin but did not have previous cesarean section (control group).

There was no statistical difference between the two groups when comparing maternal age, gravidity, gestational age and birth weight. There was significant difference in the parity. The study group has slightly higher mean parity compared to the control, 2.71 and 2.13 , respectively. The gravidity ranged from 1-15 and 2-16 in the control and study group, respectively. The parity ranged from $0-11$ and 1-14 in the control and study groups, respectively (Table 1).

The method of induction in both groups was prostaglandin E2 vaginal suppository or gel. The number of doses ranged from one dose to a total of eight doses. Different dose strengths were used for both groups and this includes $1 \mathrm{mg}, 1.5 \mathrm{mg}$ and $3 \mathrm{mg}$. Oxytocin was used in

Table 1. Baseline characteristics of control and study groups.

\begin{tabular}{cccc}
\hline & $\begin{array}{c}\text { Control group } \\
\text { (IOL in un- } \\
\text { scarred uterus) }\end{array}$ & $\begin{array}{c}\text { Study group } \\
\text { (IOL with pre- } \\
\text { vious CS) }\end{array}$ & $P$ value \\
\hline Age (SD) & $29.55(6.84)$ & $30.18(6.18)$ & 0.39 \\
Gravidity & $3.66(2.82)$ & $4.16(2.60)$ & 0.09 \\
Parity & $2.13(2.32)$ & $2.71(2.34)$ & 0.026 \\
Gestational Age & $38.56(3.85)$ & $38.85(4.11)$ & 0.52 \\
Birth Weight & $3.02(0.71)$ & $3.13(0.76)$ & 0.08 \\
\hline
\end{tabular}


labour when contractions were not adequate. The indications for induction of labor were mainly due to post-term pregnancy or decreased fetal movements in both groups. Other indications included diabetes, hypertensive disorders, intrauterine fetal death, medical disorders and spontaneous rupture of membranes. Table 2 shows the various indications for induction of labor for both groups as frequency and percentage.

There was no statistically significant difference in the rate of vaginal delivery between the study and control groups, $68.3 \%$ and $79.5 \%$ (p value 0.3 ), respectively. Cesarean section was performed due to fetal distress, failure to progress, failed induction, patient's refusal to continue induction and other reasons. The only significant difference between control and study group was the rate of Cesarean section due to failure to progress ( $\mathrm{P}$ value $=0.0007)$ (Table 3 ).

There was one case of uterine rupture in the control group and four cases of uterine rupture in the study group. We included only true uterine rupture where the whole uterine thickness was torn. In the period 1992-2009, there was 3032 cases of prostaglandin induction of labor in patients without previous Cesarean section. The rate of uterine rupture after prostaglandin induction of labour in patients with previous Cesarean section was 75 times higher than those without previous Cesarean section, $2.5 \%$ and $0.033 \%$, respectively. Among the uterine ruptures there was only one case of cesarean hysterectomy after uterine rupture in the control group. There were two neonatal deaths after uterine rupture in the study group.

Table 2. Indications for induction of labor in control and study groups.

\begin{tabular}{ccc}
\hline Indication for IOL & $\begin{array}{c}\text { Study group [n } 161 \\
(\%)]\end{array}$ & $\begin{array}{c}\text { Control group [n161 } \\
(\%)]\end{array}$ \\
\hline Post term pregnancy & $60(37.3 \%)$ & $80(49.7 \%)$ \\
Decreased fetal move- & $28(17.4 \%)$ & $17(10.6 \%)$ \\
ment & $22(13.7 \%)$ & $24(14.9 \%)$ \\
Diabetes & $10(6.2 \%)$ & $8(5 \%)$ \\
SROM & $10(6.2 \%)$ & $10(6.2 \%)$ \\
PIH \& HTN & $8(5 \%)$ & $9(5.6 \%)$ \\
IUFD & $23(14.3 \%)$ & $13(8.1 \%)$ \\
Other & &
\end{tabular}

Table 3. Mode of delivery in control and study groups.

\begin{tabular}{cccc}
\hline Mode of delivery & Control & Study & $P$ value \\
\hline $\begin{array}{c}\text { Vaginal delivery } \\
\text { Cesarean section for } \\
\text { fetal distress }\end{array}$ & 128 & 110 & 0.3 \\
$\begin{array}{c}\text { Cesarean section for } \\
\text { failure to progress }\end{array}$ & 5 & 12 & 0.2 \\
$\begin{array}{c}\text { Cesarean section for } \\
\text { failed induction } \\
\text { Other }\end{array}$ & 3 & 24 & 0.0007 \\
\hline
\end{tabular}

\section{Discussion}

One of the major concerns in our area is the rising rate of Cesarean section deliveries. The Cesarean section rate increased markedly in our hospital from 8\% in 1992 to $23 \%$ in 2009. This higher rate combined with larger family size and closer spacing in our community will inevitably lead to large number of women with multiple Cesarean sections. The increased morbidity unique to women who undergo multiple cesarean deliveries is well documented [8].

An effective strategy to decrease the cesarean section rate is the promotion of VBAC. Safe induction methods that enhance VBAC success rate without increasing mortality and morbidity should be evaluated. Prostaglandin E2 has been used extensively for labor induction in term pregnancies. There are many studies looking at induction of labour in women with one previous cesarean section, but they collect all methods of induction as one group $[9,10]$. This will affect the results greatly, as patients who require prostaglandin are different from those who need only artificial rupture of membranes or oxytocin. To the best of our knowledge this is the largest series of prostaglandin induction of labour in women with one previous cesarean section.

In our study the overall vaginal birth after prostaglandin induction of labor in women with one previous CS was $68.3 \%$ which compared favourably with the reported rate of $74 \%$ VBAC rate in women who went into spontaneous labour [11].

There are no recent randomised controlled trails of labour induction in women with previous cesarean section [12]. There is one controlled randomised study comparing weekly administration of prostaglandin gel to expectant management in women with prior cesarean delivery [13]. However, this is not applicable to majority of patients who require induction due to various medical and obstetric reasons where pregnancy should be terminated within 24-48 hours. Observational studies indicate that there is an increased risk of uterine rupture and adverse fetal outcomes, especially when prostaglandins are used [14]. In our study the rate of uterine rupture after prostaglandin induction of labour with or without previous Cesarean was $2.5 \%$ and $0.033 \%$, respectively. This is similar to the data shown by other investigators [10-16]. The risk of uterine rupture is influenced by many factors including birth weight, gestational age, race, country and maternal characteristics $[17,18]$.

The American College of Obstetricians and Gynecologists discourages the use of prostaglandins for cervical ripening and induction of labour [19]. They state that oxytocin was not precluded. Furthermore, they state that if there were clear and compelling clinical indications for 
induction of labour, that the potential increased risk of uterine rupture should be discussed.On the other hand, the Royal College of Obstetricians and Gynecologists encourages the use of prostaglandins in preference to oxytocin for induction of labour in general, and although they also emphasises the need for careful consideration for the indications and the woman's wishes, they state that in the case of trial of labour in women with prior Cesarean delivery 'vaginal prostaglandins appear to be safe' [20].

In a systemic review comparing maternal morbidity following a trail of labor versus elective repeat cesarean delivery (ERCS), it is found that the higher risk of uterine rupture in women planning VBAC than ERCS is counterbalanced by reduction of maternal morbidity, uterine rupture/dehiscence and hysterectomy when VBAC is successful [14]. Probably other methods of induction of labour should be considered in these patients. Currently, we are conducting a randomised controlled study about induction of labour in women with prior Cesarean delivery using either prostaglandin E2 gel or mechanical dilatation of the cervix with Foley's catheter.

In a recent population-based registry study, it was found that induction of labour by prostaglandins significantly increased the odds for uterine rupture compared with spontaneous labour in women with previous cesarean section [21].

At present, due to the lack of good evidence about the safety of prostaglandin induction of labor in women with one previous cesarean section, it should be only used after detailed counseling of the patient about the increased risk of uterine rupture. Other confounding factors for uterine rupture should also be kept in mind and careful selection of patients for induction of labor in women with previous section should be done. Other methods of labor induction like mechanical dilatation of the cervix should be evaluated in controlled randomised studies. Larger, ideally prospective, studies with information on dose and type of induction agent, duration of labour and underlying risk factors are needed.

\section{Acknowledgments}

We thank all the midwives and nurses in the labor room, the staff in the medical record department at King Fahad University Hospital.

\section{Ethical Approval}

Approval of the medical director of King Fahad University Hospital and director of the medical record department was obtained to access the hospital data and patients' record.

\section{REFERENCES}

[1] J. Guise, M. Berlin, M. McDonagh, P. Oserweil, B. Chan and M. Helfand, "Safety of Vaginal Birth after Cesarean: A Systemic Review,” Obstetrics \& Gynecology, Vol. 103, No. 3, 2004, pp. 420-429. doi:10.1097/01.AOG.0000116259.41678.f1

[2] B. E. Hamilton, J. A. Martin and S. J. Ventura, "Birth: Preliminary Data for 2007," National Vital Statistics Reports, Vol. 57, No. 12, 18 March 2009, pp. 1-23.

[3] G. Goumalatsos and R. Varma, "Vaginal Birth after Cesarean Section: A Practical Evidence-Based Approach," Obstetrics Gynecology \& reproductive medicine, Vol. 19, No. 7, 2009, pp. 178-186.

[4] F. Althabe and J. F. Belizan, "Caesarean Section: The Paradox,” The Lancet, Vol. 368, 2006, pp. 1472-1473. doi:10.1016/S0140-6736(06)69616-5

[5] "Central Department of Statistics and Information," Census 2004. http://www.cdsi.gov.sa/pdf/sharqiyah.pdf

[6] F. W. Makoha, H. M. Felimban, M. A. Fathuddien, F. Roomi and T. Ghabra, "Multiple Cesarean Section Morbidity," International Journal of Gynecology \& Obstetrics, Vol. 87, No. 3, 2004, pp. 227-232. doi:10.1016/j.ijgo.2004.08.016

[7] M. G. Rosen, J. C. Dickinson and C. L. Westhoff, "Vaginal Birth after Cesarean: A Meta-Analysis of Morbidity and Mortality,” Obstetrics \& Gynecology, Vol. 77, No. 3, March 1991, pp. 465-470.

[8] R. M. Silver, M. B. Landon, D. J. Rouse, K. J. Leveno, C. Y. Sponge, E. A. Thom, et al., "Maternal Morbidity Associated with Multiple Repeat Cesarean Deliveries,” $\mathrm{Ob}$ stetrics \& Gynecology, Vol. 107, No. 6, 2006, pp. 1226-1232. doi:10.1097/01.AOG.0000219750.79480.84

[9] S. I. Kayani and Z. Alfirevic, "Uterine rupture after induction of labour in women with previous caesarean section,” British Journal of Obstetrics and Gynaecology, Vol. 112, No. 12, 2005, pp. 451-455.

[10] M. J. A. Turner, G. Angew and H. Langan, "Uterine Rupture and Labour after a Previous Low," Transverse Cesarean Section, British Journal of Obstetrics and Gynaecology, Vol. 113, No. 11, 2006, pp. 729-732.

[11] G. Angew and M. J. Turner, "Vaginal Prostaglandin Gel to Induce Labour in Women with One Previous Caesarean Section," Journal of Obstetrics and Gynaecology, Vol. 29, No. 3, 2009, pp. 209-211. doi:10.1080/01443610902743789

[12] J. Dodd and C. Crowther, "Vaginal Birth after Cesrean versus Elective Repeat Cesarean for Women with a Single Prior Cesarean Birth: Asystemic Review of the Literature," Australian and New Zealand Journal of Obstetrics and Gynecology, Vol. 44, 2004, pp. 387-391. doi:10.1111/j.1479-828X.2004.00257.X

[13] W. F. Rayburn, L. N. Gittens, M. J. Lucas, S. A. Gall and M. E. Martin, "Weekly Administration of Prostaglandin E2 Gel Compared with Expectant Management in Women with Previous Cesareans," Obstetrics and Gynecology, Vol. 94, No. 2, 1999, pp. 250-254. doi:10.1016/S0029-7844(99)00300-2

[14] O. M. McNally and M. J. Turner, "Induction of Labor after 1 previous Cesarean Section,” Australian and New 
Zealand Journal of Obstetrics and Gynecology, Vol. 39, No. 4, 1999, pp. 425-429.

doi:10.1111/j.1479-828X.1999.tb03126.x

[15] A. C. Rossi and V. D’Addario, “Maternal Morbidity Following a Trial of Labor after Cesarean Section vs Elective Repeat Cesarean Delivery: A Systemic Review with Metaanalysis," American Journal of Obstetrics and Gynecology, Vol. 199, No. 3, 2008, pp. 224-231. doi:10.1016/j.ajog.2008.04.025

[16] A. G. Cahill, D. M. Stamilio, A. O. Odibo, J. F. Peipert, E. J. Stevens and G. A. Macones, "Does a Maximum Dose of Oxytocin Affect Risk of Uterine Rupture in Candidates for Vaginal Birth after Cesarean Delivery?” American Journal of Obstetrics and Gynecology, Vol. 197, No. 495, 2007, pp. e1-e5.

[17] M. Kaczmarczyk, P. Sparen, P. Terry and S. Cnattingius, "Risk Factors for Uterine Rupture and Neonatal Consequences of Uterine Rupture: A Population-Based Study of Successive Pregnancies in Sweden," British Journal of Obstetrics and Gynaecology, Vol. 114, No. 10, 2007, pp.
1208-1214. doi:10.1111/j.1471-0528.2007.01484.X

[18] G. J. Hofmeyr, L. Say and A. M. Gulmezoglu, "WHO Systemic Review of Maternal Mortality and Morbidity: The Prevalence of Uterine Rupture," British Journal of Obstetrics and Gynaecology, Vol. 112, No. 9, 2005, pp. 1221-1228. doi:10.1111/j.1471-0528.2005.00725.x

[19] ACOG Committee Opinion No. 271, "Induction of Labor for Vaginal Birth after Cesarean Delivery,” Obstetrics and Gynecology, Vol. 99, 2002, pp. 679-680.

[20] M. S. McDonagh, P. Osterweil and J.-M. Guise, “The Benefits and Risks of Inducing Labour in Patients with Prior Caesarean Delivery: A Systemic Review,” British Journal of Obstetrics and Gynaecology, Vol. 112, No. 8, 2005, pp. 1007-1015. doi:10.1111/j.1471-0528.2005.00623.x

[21] I. Al-Zirqi, B. Stray-Pedersen, L. Forsen and S. Vangen, "Uterine Rupture after Previous Cesarean Section," British Journal of Obstetrics and Gynaecology, Vol. 117, No. 11, 2010, pp. 809-820. 